\title{
Process of translation and adaptation of the Nurse Professional Competence (NPC) Scale
}

\author{
Jan Nilsson *1,2, Ann Gardulf ${ }^{2,3}$, Margret Lepp ${ }^{4,5}$ \\ ${ }^{1}$ The Department of Health Sciences, Faculty of Health, Science and Technology, Karlstad University, Karlstad, Sweden \\ ${ }^{2}$ The Japanese Red Cross Institute for Humanitarian Studies, Tokyo, Japan \\ ${ }^{3}$ The Unit for Clinical Nursing Research and Clinical Research in Immunotherapy, Division of Clinical Immunology, Department \\ of Laboratory Medicine, Karolinska Institutet at Karolinska University Hospital, Huddinge, Stockholm, Sweden \\ ${ }^{4}$ Institute of Health and Care Science, The Sahlgrenska Academy, University of Gothenburg, Gothenburg, Sweden \\ ${ }^{5}$ Østfold University College, Halden, Norway
}

Received: August 13, 2015

DOI: $10.5430 /$ jnep.v6n $1 \mathrm{p} 100$
Accepted: September 20, $2015 \quad$ Online Published: October 20, 2015

URL: http://dx.doi.org/10.5430/jnep.v6n1p100

\begin{abstract}
Professional competence in nursing is of crucial importance for high quality care and patient related outcomes. A new instrument for measuring competence in nursing has been developed by a Swedish research group. The instrument is called the Nurse Professional Competence (NPC) Scale and is based on national guidelines, and the WHOs European Strategy for Nursing and Midwifery. The NPC Scale consists of 88 items distributed in eight competence areas, and measures self-reported professional competence. The target groups are nursing students at the point of graduation and registered nurses. As the NPC Scale has rendered great interest from researchers internationally, the NPC research group decided to translate the Scale into English to facilitate international use of the instrument. The aim of this article was to describe the translation process used to create an English version of the NPC Scale. This article describes the translation process from Swedish to English and its challenges. The translation process resulted in an English version of the NPC Scale ready for internationally usage.
\end{abstract}

Key Words: Competence in nursing, Instrument, NPC Scale, Nursing education, Professional nursing, Translation

\section{INTRODUCTION}

Nurses of tomorrow are expected to take a leading role in managing changes in the area of healthcare and the advancement of health. ${ }^{[1]}$ In order to take on this role, nurses need to have considerable competence in all aspects of nursing.

A high degree of clinical competence among nurses has been shown to be associated with lower mortality rates among patients within hospital settings. ${ }^{[2-5]}$ The development and need for healthcare on a global level will have an impact on education related to the role and function of the future nurse. By using valid and reliable instruments to measure and fol- low up nurses' competencies, it is possible to adjust curricula for nursing education and set up competence development programmes for nurses in clinical care. In an editorial, Bergbom $^{[6]}$ highlighted the need for development and research of methods that fit the unique phenomena in caring sciences. It is vital to use methods that have the required properties to reflect the core of the discipline. Therefore, questionnaires and instruments measuring vital phenomena reflecting the core of caring are needed.

In Sweden, the Nurse Professional Competence (NPC) Scale ${ }^{[7]}$ was developed based on formal competence require-

*Correspondence: Jan Nilsson; Email: nilj@kau.se; Address: The Department of Health Sciences, Faculty of Health, Science and Technology, Karlstad University, Karlstad, Sweden. 
ments for registered nurses, ${ }^{[8]}$ which in turn are influenced by the World Health Organization's (WHO) European Strategy for Nursing and Midwifery to improve and unify education programmes for nurses and midwives. ${ }^{[9]}$ The NPC Scale consists of 88 items and covers eight competence areas: nursing care, value-based nursing care, medical/technical care, teaching/learning and support, documentation and information technology, legislation in nursing and safety planning, leadership in and development of nursing care, and education and supervision of staff/students. ${ }^{[7]}$ In addition, the following six core competencies have been identified internationally as necessary for all education in the care professions: personcentered care, teamwork in collaboration, evidence-based practice, quality improvement, safe care, safety and informatics. ${ }^{[10]}$ These six competencies have been included in the strategy of The Swedish Association of Nurses since year 2010, and their content corresponds well to the NPC Scale.

The NPC Scale has proved to be reliable and valid, ${ }^{[7]}$ and has been used in several published studies including both nursing students on the point of graduation and registered nurses with professional experience, ${ }^{[11-13]}$ as well as in publications in process by Theander et al. ${ }^{[14]}$ and Nilsson et al. ${ }^{[15]}$ Furthermore, the NPC Scale has been presented at both national medical conferences ${ }^{[16]}$ and international nursing conferences, ${ }^{[17]}$ and has yielded great interest from researchers in Europe, South and North America, and Asia. Therefore, the Swedish NPC research group decided to translate the NPC Scale into English to facilitate international use of the instrument.

The aim of this paper was to describe the translation process used to create an English version of the NPC Scale.

\section{Process of translation}

The English version of the NPC Scale was developed in eight steps, influenced by WHO recommendations. ${ }^{[18]}$ The process of translation and adaptation of instruments recommended by the WHO consists of the following stages: forward translation, expert-panel back translation, pre-testing, cognitive interviews and final version. However, the translation process of the NPC Scale required additional three steps.

\section{Step 1 - Forward translation from Swedish to English by a professional translator}

The translation process started by identifying a bilingual professional translator, with English as mother tongue and proficiency in the Swedish language. The translator made a translation of the NPC Scale, from Swedish to English (first version).

Published by Sciedu Press

\section{Step 2 - Expert panel review and revision of the first En-} glish version

The authors (JN, AG and ML), who are bilingual in Swedish and English, formed the expert panel. All members of the expert panel have long experience in international clinical healthcare work and global healthcare development issues within the WHO and the Red Cross/Red Crescent Organisation. Their experiences have included translation of healthrelated documents, and all authors have considerable experience in instrument development. Moreover, one of the authors (AG) was a key person in her role as Government Chief Nurse in developing the formal competence requirements for registered nurses in Sweden. ${ }^{[8]}$

The expert panel reviewed the first version of the translated NPC Scale with special focus on identifying and editing inadequate nursing concepts in the translation. Furthermore, the work included checking for any discrepancies between the forward translation and the original Swedish version, keeping in mind the specific language of the nursing students/registered nurses responding to the NPC Scale. The expert panel also considered that the original terms had been translated in the most relevant way, e.g., that nursing, caring and technical terms could most likely be clearly understood by the targeted respondents.

The work of the expert panel resulted in the revision of some words, e.g., specific nursing concepts, and step 2 resulted in an edited second English version of the NPC Scale.

\section{Step 3 - Back translation from English to Swedish}

A bilingual translator, whose mother tongue is Swedish, then translated the NPC Scale from English to Swedish. The translator, a professor in nursing at a university in Sweden, had previous experience in translating the Nursing Diagnoses (NANDA) Manual from English to Swedish. The translator's experience was highly valued with regard to the trustworthy translation of specific nursing concepts.

\section{Step 4 - Expert panel review and revision of the Swedish version}

The expert panel reviewed and compared the back translation of the NPC Scale with the original Swedish version of the NPC Scale. There were 16 word discrepancies (e.g., the use of specific words such as team cooperation $v s$. team work, prevent $v s$. prevention, and handle vs. manage) that were discussed among the members of the expert panel until agreement was reached. Some words and expressions were adjusted and a revised third English version was produced. 
Step 5 - Review of suggested English version by professional English language editor

The fifth step of the translation process involved the third English version of the NPC Scale being reviewed and edited by a professional language editor with English as mother tongue and extensive experience of editing nursing manuscripts and documents. Only minor strictly language-related corrections (e.g., alleviate this through adequate measures vs. alleviate this by taking adequate measures), were suggested by the professional language editor and accepted by the expert panel, but no revisions of specific nursing concepts were proposed.

\section{Step 6 - Expert panel - assessment of language editing}

The expert panel considered the suggested revisions made by the professional English language editor. The changes comprised only minor language corrections. All suggested revisions were accepted and led to a fourth English version.

\section{Step 7 - Pre-testing and cognitive interviews}

The translated fourth English version of the NPC Scale was pre-tested by the expert panel on two native English-speaking professionals, who answered the scale in writing. One was a Senior Lecturer working at a university in the UK and the other was a registered nurse working in Sweden. The pre-test also included individual interviews with the two professionals regarding their cognitive understanding, to detect items that were not understood as intended by the expert panel. The outcome was summarized by the expert panel for further use in step 8.

\section{Step 8 - Expert panel review of the pre-tested version}

The expert panel reviewed the outcome of step 7 which resulted in a few revisions related to the use and flow of words in a sentence. For example, the expression "care chain" was changed to "chain of care". This was the last step in the process of translation, which resulted in a final English version of the NPC Scale.

\section{Discussion}

This paper describes the translation process used to produce an English version of the NPC Scale. As mentioned in the introduction the NPC Scale consists of 88 questions covering eight competence areas ${ }^{[7]}$ Self-reported competence for each of the items are stated on a scale with four response alternatives: $1=$ to a very low degree to $4=$ to a very high degree. A short description of the 88 items is available in one of the NPC publications. ${ }^{[7]}$

The translation from Swedish to English of the NPC Scale has proved to be a challenging and time-consuming process. 102
Before taking on a mission of this dignity it is important to consider the time aspect and allocate continuous periods of time for the translation process. A scale/questionnaire such as this often consists of more words than believed that need to be handled; in this case the NPC Scale consists of a total of 1061 words. Another important aspect is the functionality of the expert panel; the work demands a good relationship, trust and advanced teamwork. Based on a trustingly teamwork the practical process of the translation can shift between physical and virtual meetings. ${ }^{[19]}$

Lessons learnt from the translation process were several; we would directly consult a professional translator with qualified knowledge in the context of nursing, as it otherwise can prolong the translation process. In hindsight, the most challenging issue of all is thus identifying professional translators, who are skilled in both the language and the specific nursing context. This became obvious in step 4 where the comparison of the back translation of the Scale with the original Swedish version of the NPC Scale done by a bilingual professor in nursing resulted in that only 16 out of 1,061 $(1.5 \%)$ of the words where suggested to be corrected. Moreover, testing, evaluating and choosing the correct nuance of specific words in order to find the most appropriate translation is an advanced challenge.

The fact that the NPC Scale is based on international guidelines $^{[9]}$ and its content corresponds well to what internationally has been identified as six core competencies ${ }^{[10]}$ for health professionals ensures the content and usability of the Scale in an international context. The NPC Scale can be used to evaluate the outcome of nursing education programs, to assess nurses' competences in relation to the needs in health care organizations and to identify self-reported competences. $^{[7,11-13]}$

The English version of the NPC Scale is now ready to be used in a full-scale research project among English-speaking nurse students and/or registered nurses. An example is the European Network Nursing Academies (ENNA) who has decided to use the NPC Scale in a joint European research project. In addition, the NPC group has received request from scholars all around the world interested in using the NPC Scale in their own research and development of nursing education and audit of the nursing care.

\section{Concluding Remarks}

The final English version of the instrument is a result of all the iterations described above, which have been documented. The composition of the expert panel has been an asset in the work, as the authors are grounded in both the specific nurs- 
ing context and the English language. We hope that the final English version of the NPC Scale will be an important contribution to stimulate international research regarding nurses'

\section{REFERENCES}

[1] The future of nursing: Leading change, advancing health [Internet]. Institute of Medicine. 2010. Available from: http://books .nap. edu/openbook.php?record_id=12956\&page $=$ R1

[2] Aiken LH, Smith HL, Lake ET. Lower Medicare mortality among a set of hospitals known for good nursing care. Medical Care. 1994; 32(8): 771-87. http://dx.doi.org/10.1097/00005650-199 408000-00002

[3] Aiken LH, Clarke SP, Cheung RB, et al. Educational levels of hospital nurses and surgical patient mortality. Journal of the American Medical Association. 2003; 209(12): 1617-23. PMid:14506121 http://dx.doi.org/10.1001/jama.290.12.1617

[4] Aiken LH, Clarke SP, Sloane DM, et al. Effects of hospital Care environment on patient mortality and nurse outcome. Journal of Nursing Administration. 2008; 38(5): 223-29. PMid:18469615 http: //dx.doi.org/10.1097/01. NNA.0000312773.42352.d7

[5] Aiken LH, Sloane DM, Bruyneel L, et al. Nurse staffing and education and hospital mortality in nine European countries: a retrospective observational study. Lancet. 2014; 24(9931): 1824-30. http://dx.doi.org/10.1016/S0140-6736(13)62631-8

[6] Bergbom I. Methodological research and research about methods in caring sciences. Scand J Caring Sci. 2010; 24(Suppl 1): 1.

[7] Nilsson J, Johansson E, Egmar AC, et al. Development and validation of a new tool measuring nurses self-reported professional competence-the nurse professional competence (NPC) Scale. Nurse Educ Today. 2014; 34(4): 574-80. PMid:23938092 http://dx. doi.org $/ 10.1016 / j$.nedt .2013 .07 .016

[8] The National Board of Health and Welfare. Competence Requirements for Registered Nurses. Stockholm. Sweden. 2005

[9] WHO. Nurses and midwives for health. WHO European Strategy For Nursing And Midwifery Education, Guidelines for Member States on the Implementation of the Strategy. 2001.

[10] Leksell J, Lepp M. Sjuksköterskans kärnkompetenser. Stockholm: Liber. (The Nurse's Core Competencies). Stockholm: Liber, 2013. competencies.

CONFLicts OF INTEREST Disclosure

None of the authors declare a conflict of interest.
[11] Nilsson J, Carlsson M, Johansson E, et al. Nursing in a Globalized World: Nursing Students with International Study Experience Report Higher Competence at Graduation. Open Journal of Nursing. 2014; 4: 848-58. http://dx.doi.org/10.4236/ojn. 2014.412090

[12] Leksell J, Gardulf A, Nilsson J, et al. Self-reported conflict management competence among nursing students on the point of graduating and registered nurses with professional experience. J Nurs Educ Pract. 2015; 5(8): 82-89. http://dx.doi.org/10.5430/jnep.v5n8p7

[13] Gardulf A, Nilsson J, Florin J, et al. The nurse professional competence (NPC) Scale: Self-reported competence among nursing students on the point of graduation. In press, Nurse Education Today.

[14] Theander K, Wilde-Larsson B, Carlsson M, et al. Adjusting to future demands in healthcare - The impact of curriculum changes on nursing students' self-reported professional competence. Submitted manuscript.

[15] Nilsson J, Johansson E, Carlsson M, et al. Disaster nursing: Selfreported competence of nursing students and registered nurses, with focus on their readiness to manage violence, serious events and disasters. Accepted for publication, Nurse Education in Practice.

[16] Gardulf A, Nilsson J, Carlsson M, et al. Ger svensk sjuksköterskeutbildning kunskap som bidrar till framtidens hälsa? Medicinska Läkarstämman, Stockholm. 2012. Available from: http://abst rakt.sls.se/viewSam . asp?action=view\&nSamId=10595

[17] Patel H, Al-Halabi OJ, Bergbom I, et al. Leadership, Learning and Research in Nursing and Midwifery. Conference Guide and Abstract Book. Sigma Theta Tau International Honor Society 2nd European Regional Conference. Gothenburg, Sweden. Ale Trycktema, Bohus. 2014.

[18] WHO. Process of translation and adaptation of instruments. [Internet]. Geneva: World Health Organization. 2015. Available from: http://www.who.int/substance_abuse/research_t ools/translation/en/

[19] Bagshaw D, Lepp M, Zorn CR. International Collaboration: Building Teams and Managing Conflicts. Conflict Resolution Quarterly. 2007; 24(4): 433-446. http://dx.doi.org/10.1002/crq.183 